\title{
Erratum
}

\section{ESTIMATION OF BACOSIDE-A IN BACOPA MONNIERI AERIAL PARTS USING TLC DENSITOMETRY}

\section{RAJESH KUMAR $^{\mathrm{a}}{ }^{1}$, TEJPAL SINGH ${ }^{1}$, DEEPAK KUMAR ${ }^{2}$, MANDEEP SINGH ${ }^{1}$, SANDEEP KAUR $^{1}$, RAJEEV GARG $^{3}$}

${ }^{1}$ Rayat-Bahra Institute of Pharmacy, Hoshiarpur, Punjab, India, ${ }^{2}$ Department of Pharm. Sciences and Drug Research, Punjabi University, Patiala, Punjab, India, ${ }^{3}$ ASBASJSM College of Pharmacy, Bela, Ropar, Punjab, India

Email: rgpharma@gmail.com

Ref: http://www.ijppsjournal.com/Vol7Issue12/8865.pdf

\section{ABSTRACT}

Objective: The objective of the present work was to formulate and evaluate a stable, odour free garlic powder loaded floating matrix tablet for the treatment of peptic ulcers.

Methods: A gastro-retentive floating matrix tablet (FMT) formulation of garlic powder (GP) was prepared using various concentrations of hydroxypropyl methylcellulose K4M (HPMC K4 M) and effervescent system (sodium bicarbonate and citric acid in 1:1\% w/w) to achieve desirable floating time (FT), floating lag time (FLT) and drug release. Wet granulation method was selected using ethanol as a binder for preparation of tablet. $3^{2}$ full factorial designs were used for selection of suitable polymer concentration and effervescent system. Nonenteric film coating was applied to mask GP odour.

Results: It was observed that FMT with optimum quantities of HPMC K4M and the effervescent system showed $97 \%$ of drug release in 12 h with FT up to $10 \mathrm{~h}$ and minimum FLT of 3 min. There was no significant change in FLT, FT and drug content during the stability study of FMT.

Conclusion: A stable, sustained release FMT of GP tablets using HPMC K4M and an effervescent system was successfully prepared. This formulation can overcome problems of taste and odour masking, gastric irritation, and loss of active constituents present in garlic

Keywords: Garlic powder, H. pylori, Floating time, Floating Lag time, Floating Matrix tablet, HPMC K4M

1Rayat-Bahra Institute of Pharmacy, Hoshiarpur, Punjab, India

${ }^{a}$ IKG Punjab Technical University, Kapurthala

2Department of Pharm. Sciences and Drug Research, Punjabi University, Patiala, Punjab, India

${ }^{3}$ ASBASJSM College of Pharmacy, Bela, Ropar, Punjab, India

${ }^{3}$ Corresponding author:

Dr Rajeev Garg

Email: rgpharma@gmail.com 